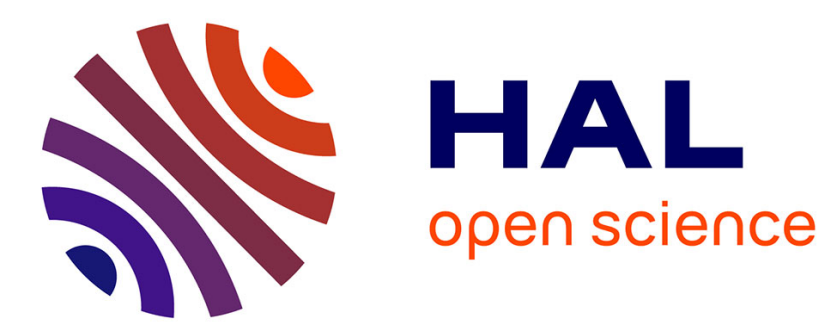

\title{
Integration of a parallel cable-driven robot on an existing building façade
}

Jean-Baptiste Izard, Marc Gouttefarde, Cédric Baradat, David Culla, Damien Sallé

\section{- To cite this version:}

Jean-Baptiste Izard, Marc Gouttefarde, Cédric Baradat, David Culla, Damien Sallé. Integration of a parallel cable-driven robot on an existing building façade. 1st International Conference on CableDriven Parallel Robots (2012), 2012, Stuttgart, Germany. pp.149-164, 10.1007/978-3-642-319884_10. lirmm-00737648

\section{HAL Id: lirmm-00737648 https://hal-lirmm.ccsd.cnrs.fr/lirmm-00737648}

Submitted on 31 May 2021

HAL is a multi-disciplinary open access archive for the deposit and dissemination of scientific research documents, whether they are published or not. The documents may come from teaching and research institutions in France or abroad, or from public or private research centers.
L'archive ouverte pluridisciplinaire HAL, est destinée au dépôt et à la diffusion de documents scientifiques de niveau recherche, publiés ou non, émanant des établissements d'enseignement et de recherche français ou étrangers, des laboratoires publics ou privés. 


\title{
Integration of a Parallel Cable-Driven Robot on an Existing Building Façade
}

\author{
Jean-Baptiste Izard, Marc Gouttefarde, Cedric Baradat, David Culla \\ and Damien Sallé
}

\begin{abstract}
In order to use a cable-driven parallel robot to inspect an existing surface, a straightforward solution consists in fixing the robot components on this surface. In most cases, however, there are conditions that limit these fixations, for example structural reasons since the frame of the surface has probably not been specifically calculated to withstand the forces generated by the parallel cable-driven robot. In the particular case of inspection of the façade of a building, civil engineering specifications apply, which may drastically reduce the engineering possibilities from the point of view of the parallel cable-driven robot designers. This paper introduces a detailed example of implementation of a parallel cable-driven robot on the Media-TIC building located in Barcelona in Spain. In this highly technological building, the main façade parallel cable-driven robot in intended to work as a sensor for monitoring the environment, but also as an interface between the building and its occupiers. The various constraints - due to normative, structural and aesthetic reasons- that were tackled are described in the paper, along with the elected detailed design of the robot that complies with these constraints.
\end{abstract}

\section{Introduction and Previous Art}

Parallel cable-driven robots are well-known to have a potentially very large workspace since very long cable lengths can easily be wound on winch drums. This advan-

\author{
J.-B. $\operatorname{Izard}(\varangle) \cdot$ C. Baradat \\ Tecnalia France, MIBI, 672 rue du Mas de Verchant, 34000 Montpellier \\ Montpellier, France \\ e-mail: jeanbaptiste.izard@tecnalia.com \\ M. Gouttefarde \\ LIRMM - UMR 5506 - CC 477, 161 rue Ada, 34095 Montpellier Cedex 5 \\ Montpellier, France \\ D. Culla $\cdot$ D. Sallé \\ Tecnalia, Mikeletegi Pasealekua, 7, 20009 - San Sebastian Gipuzkoa, Spain
}


tageous unusual property enables large-scale applications such the one consisting in setting up a parallel cable-driven robot on the façade of a building. During the construction phase of the building, as a temporary tool clamped to the structure of the building, it would be possible to safely and accurately manipulate large windows and panels to install them on the façade, with full control of the rotational degrees of freedom. Moreover, on the finished building, a vertical parallel cable-driven robot gliding on its façade would be able to perform remote visual inspection or cleaning. It may be used as a dynamic local weather station, measuring illumination at different positions on the façade to mitigate sun shade systems, but also pollution and $\mathrm{CO}_{2}$ levels. In addition, a vertical façade cable-driven robot may also be useful for pest bird scaring and to serve as a dynamic interface with the building's intelligence for the public.

Installation of such a device must respond to particular specifications as they are fixed to a structure that is not necessarily originally purposed to that use. The sidewalk below the façade may also have to be kept free from being impaired, which leads to extra caution when designing the robot in order to avoid failure that could cause harm to nearby pedestrians.

Cable-driven camera systems for sport and entertainment, such as the SkyCam [1] and SpyderCam [2] systems, are typical examples of possible integration of a parallel cable-driven robot on an existing structure, which is not specifically equipped for such an installation. In these particular cases, the drawing points for the 4 cables supporting the camera tilt and pan system are strapped to the building roof main structure as high as achievable above the winches. This solution is suitable due to the low forces that generate these systems as compared to structural forces in the building. Being in action above the public, these systems are designed with very high security factor, from 8 to 12 .

The MARIONET-Crane developed by INRIA [3, 4] as a demonstrator of a search and rescue robot is an example similar to the SkyCam and SpiderCam systems, as it is installed on structures that are not meant for that use. However, MARIONET-Crane has more degrees of freedom as it uses 6 cables. The winches are installed around the intervention site, typically on overlooking buildings, and held in place by ballast weight.

SkyCam, SpyderCam and MARIONET-Crane solutions are typically fitted for horizontal low height workspaces, in suspended under-constrained configurations. In the case of a vertical façade parallel cable-driven robot, the most drastic constraint is to reach as much of the façade surface as achievable, including high height. The robot must also be able to counteract forces perpendicular to the façade, even though the footprint of the robot along this direction is required to be much smaller than the dimensions of the building. In other words, transversal stiffness is a major issue.

Overconstrained planar cable-driven robot designs with 3 or 4 cables have been suggested in the state of art as well, which is the typical design needed for moving a platform across a surface [5]. This fully constrained design has been chosen for several research prototypes later on [6-8]. When running on a plane in two dimensions, these designs run on a flat horizontal surface, with gravity supplying the necessary stability on the transversal axis; when the surface is vertical, a device forces the plat- 

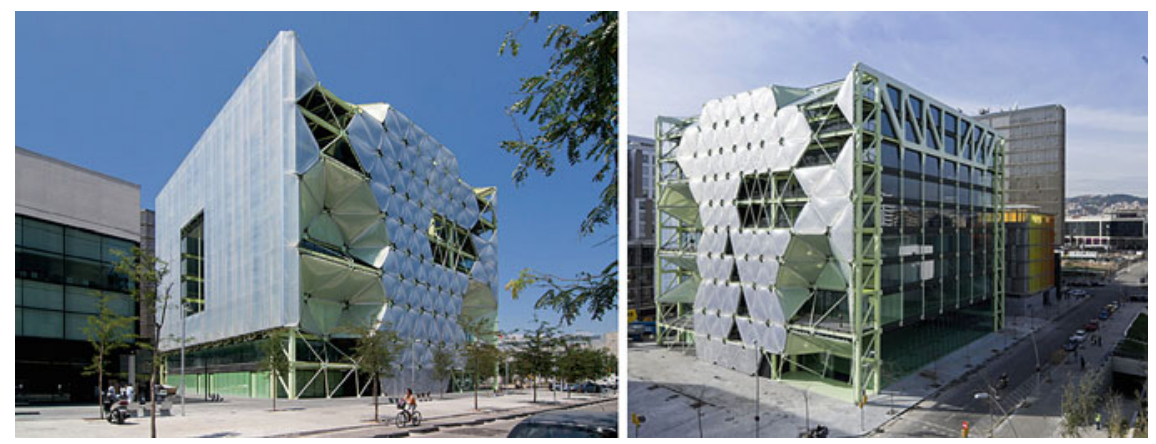

Fig. 1 Views of the Media-TIC building. Left: SE and SW façades; Right: SE and NE façades. Credits: José Miguel Hernandez, Iwan Baan

form on the surface to solve the stiffness issue. In the specific issue of the Media-TIC building, the façade is too fragile and irregular for the platform to run on it, making the overconstrained planar design unfitted with this application.

In the present paper, we discuss the different specifications that have been set to a low-profile façade parallel cable-driven robot intended to be installed on the Media-TIC building in Barcelona, Spain. The elected design is then introduced.

\subsection{Presentation of the Media-TIC Building}

Owned by El Consorci, running the Zona Franca in Barcelona, the Media-TIC building has been designed by the Cloud9 architect agency under the direction of Enric Ruiz-Geli. It is a highly technological building, with a strong focus on new technologies and concepts for achieving zero energy building at reasonable cost. The building itself will run as an incubator for SMEs on new media technologies and TICs. It is placed in an area under the control of $22 @$ Barcelona project by the city of Barcelona. This project features specific incentives for installing pilot tests of innovative solutions to be run within the district, through the 22@Urban Lab.

It is first characterized by an innovative structural design. The main structure of the building is a large steel gantry, covered with glass and ETFE cushions. Instead of being built from the ground to the top, the floors are hanged to the gantry, which liberates space both at the floors, where there is no pillar but simply cables, and at the lobby, which operates as a very wide open volume. The whole structure has been covered with a bioluminescent paint that gives it a faint glow in the night.

This gantry and hung design, enhanced by the beams running a pattern on the south-eastern façade that is driven by the strain due to the wind, give the whole structure a distributed aspect. This focus on distribution has been declined by the architect in every system of the building, from structure to energy and sensors (Figs. 1 and 2). 


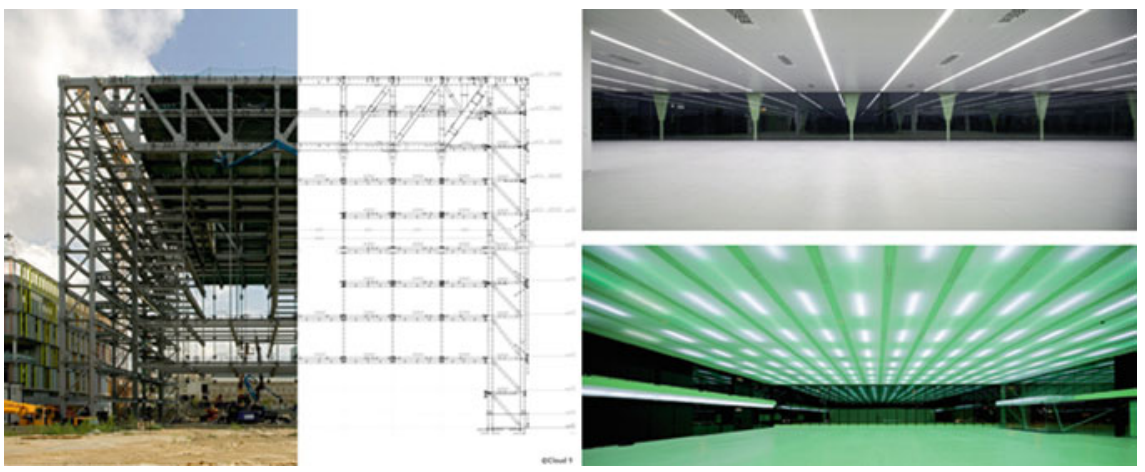

Fig. 2 Left: View of the gantry during construction. It is still visible on the NE façade. Right up: inside view of one of the floors. Right bottom: inside view of the lobby. Credits: Cloud9, Iwan Baan, Luis Ros

Indeed, the whole building is fitted with sensors, for example presence sensors that light the way of occupiers along their path. In addition, the south-eastern façade is fitted with 104 multilayer ETFE cushions, meant for mitigating sunlight, controlled by a pneumatic system based on a light flux sensor, based on an Arduino platform addressable by Ethernet that is individual for each cushion. This results in a dynamic control of the façade. On the other hand, the south-western façade is protected by another series of ETFE cushions, filled with oil mist in order to decrease heat brought by sunlight. Both of these technologies have been patented for the purpose of the Media-TIC building, and have resulted in a $20 \%$ increase of the energy efficiency of the building.

The Media-TIC building makes extensive use of the highly effective urban heat and cooling system set in place in the $22 @$ district. Solar panels on the roof are a final asset to make the building $60 \%$ more efficient in $\mathrm{CO}_{2}$ emissions than the average building in Barcelona.

Granular sensor and control throughout the building, as well as different heat mitigation systems and different sources of energy, are some other different ways for the architect to stick to the concept of a "distributed building".

\section{Specification}

Tecnalia got in contact with the architect cabinet, Cloud9, in order to install a vertical fully constrained cable-driven parallel robot on the south-eastern façade as illustrated in Fig. 3 As it was important not to distort the aesthetics and concepts of the building just as much as making the robot safe for the public and the building, the specifications include both safety and dimensioning constraints on the one hand and aesthetic constraints on the other hand. 

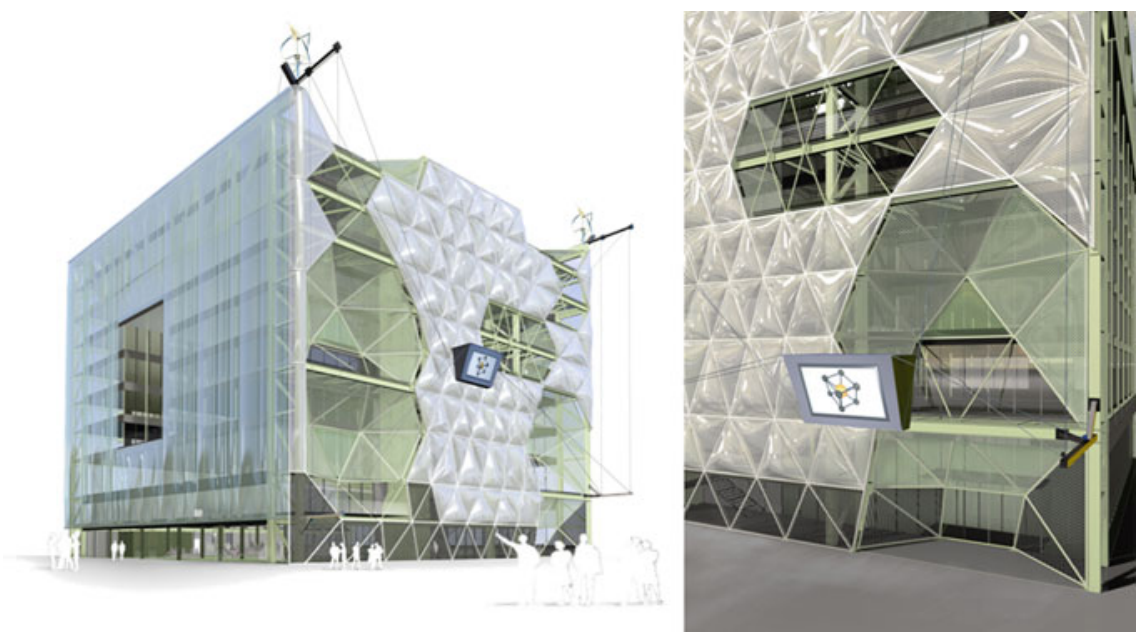

Fig. 3 Previews of the Media-TIC building with the cable-driven robot

\subsection{Tasks}

The main application for which the first drafts of the robot have been designed for is to be used as a weather station monitoring $\mathrm{CO}_{2}$ level, pollution level, temperature, humidity and light level, and as an interface between the public and the building itself. The goal according to the architect was to prove the building's intelligence, by showing data such as energy consumption of the building and data from the weather station sensors.

In addition to these tasks, the robot is foreseen to be used for visual inspection of the façade using a camera. It also proved valuable to the operator of the building that the functioning of the robot would effectively scare bird pests that could degrade the façade.

\subsection{Workspace Limits}

The limits of the workspace have been set accordingly to the tasks to be carried out. It has been agreed that the robot's interface task should be carried out at the building's terraces spread across the façade. The workspace should therefore include positions in front of each terrace, except the ones situated at the top floor since the tensions in the robot's cables are expected to rise dramatically at these positions.

In addition, every structure that holds the auxiliary systems of the robot has to fit within the building's dedicated volume, which is $37 \mathrm{~m}$ high by $43 \mathrm{~m}$ wide, and protruding out of the façade by at most $5 \mathrm{~m}$. 


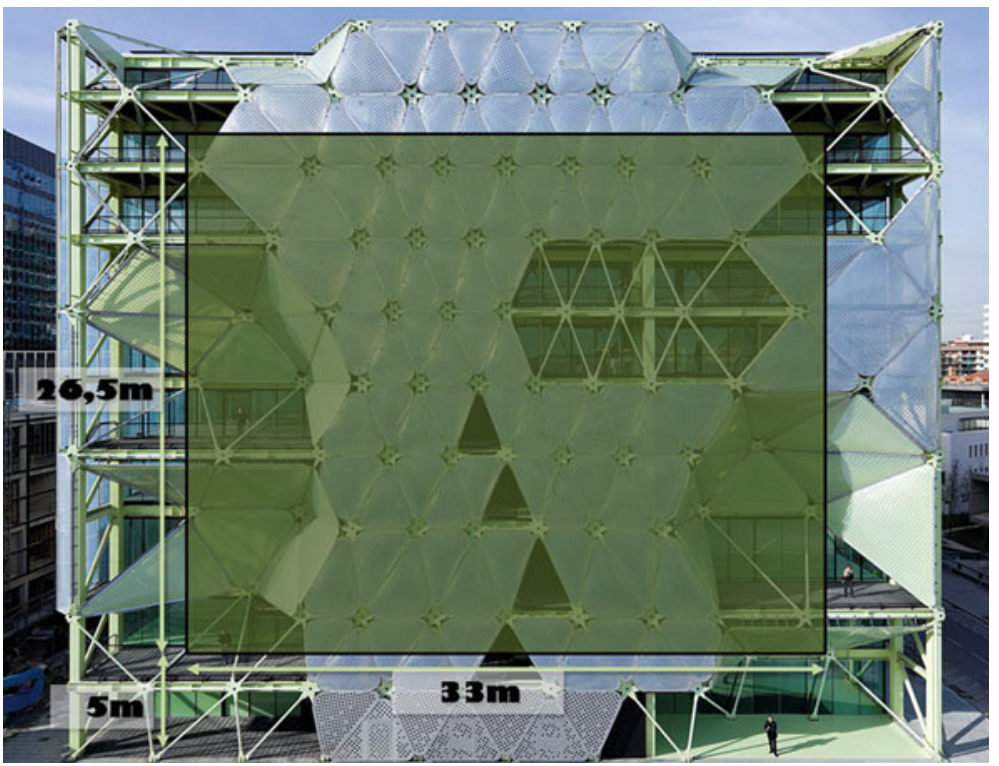

Fig. 4 Desired workspace of the parallel cable-driven robot on the layout of the Media-TIC façade

As a result, the workspace has been set to be $33 \mathrm{~m}$ wide centered on the building's width by $26 \mathrm{~m}$ high, starting $5 \mathrm{~m}$ above the ground as depicted in Fig. 4 The robot mobile platform should be able to keep a constant orientation throughout the workspace while carrying its payload.

\subsection{Building Related Constraints}

In order for the building to support the forces applied by the parallel cable-driven robot, the posts to which are attached the pulleys driving the cables to the nacelle (mobile platform) should be fixed to the main frame of the building's gantry. They may be attached by clamping, welding or drilling holes in the gantry for screws. Considering the forces that will support the posts and their direction (in mean directed towards the middle of the workspace), they should be fixed at the points where horizontal and vertical beams of the gantry are fixed together. The exact validation of the structure of the posts will be carried out by the same civil engineering company that dimensioned the Media-TIC gantry.

The winches should be placed somewhere where it is out of reach of the public, preferably on the façade to avoid long cable circulation around the building. In order to facilitate the integration of the control electronics of the robot, they should all be placed at the same position. 
The robot should withstand the same wind figures than the building itself, which is a peak wind at $160 \mathrm{~km} / \mathrm{h}$, generating up to $1,3 \mathrm{kN}$ of load on $1 \mathrm{~m}^{2}$ of surface of the building. Considering that the forces on the nacelle and the cables will be considerably high in such a wind, it has been agreed that the robot will not operate when wind is higher than $50 \mathrm{~km} / \mathrm{h}$, which is the case $5 \%$ of the year, resulting in a set wind load of $140 \mathrm{~N} / \mathrm{m}^{2}$. It should therefore withstand this wind speed when operating, and wind speed up to $160 \mathrm{~km} / \mathrm{h}$ when at rest.

A cradle should be built somewhere on the façade to fix the robot's nacelle when it is not operating. This nacelle cradle will have to support the loading of the robot when at rest, such as wind load. It will also be used for robot initialization.

Finally, it is important that the robot comply with the safety constraints of the building. Indeed, there are 4 ETFE triangular cushions on the façade that serve as smoke vents, opening wide to ensure correct ventilation of the escape stairs of the building during a fire alarm event. These smoke vents protrude from the façade surface by $3 \mathrm{~m}$ It takes $3 \mathrm{~s}$ for the smoke vents to reach their open position. During such an event, the robot should be able to go back safely to its cradle without interfering with the smoke vents.

\subsection{Norms}

Since the robot will be built above the public footway in front of the building, we chose to comply with restrictive standards according to DIN 5692: Entertainment technology-Flying systems. This standard requires a security factor of 10 in structural system of the robot, force sensors monitoring continuously the tensile forces in the cables and a routine in the control loop that stops the robot when a maximum force is reached, and finally a double brake system on the winches.

\subsection{Aesthetic and Conceptual Integration to the Building}

The parallel kinematics principles on which a parallel cable-driven robot operates are related to the distribution principle put forward by the architect during the conception of the Media-TIC building. Such features proved to be a major asset for the architect to accept the design and seize it to integrate it fully to his building. Fitting to the main principles that directed the design of Media-TIC is indeed an important step when dealing with building with such a level of conceptual design.

It is just as much important to avoid that the robot has a bad visual impact on the façade, especially because the south-eastern façade on which it is installed is the most visible. In this respect, a parallel cable-driven robot has inherent advantages since the façade is run across by cables which have a low visual impact.

Since the building aims at being self-sufficient in energy, it is important for the robot to share this characteristic to fit with the rest of the building. On Media-TIC, this 
translates into additional wind generators that have to be installed. These wind generators will provide the power needed for the robot, knowing that its speed will have to be different depending on how much energy has been harvested with the windmills in order to match with their actual production. The nacelle, which is equipped with electronic equipment (cameras, lighting, screen, wireless communications, etc.), will also be equipped with solar panels in order to compensate for its consumption.

In order to keep a low visual impact at the level of the terraces, it has been chosen that the interface between the robot and the public should be a soft interface. The typical example would be sending text messages to the robot to have it come to one specific terrace, or to carry out a path on the façade, or to send specific information about the building.

On the other hand, the architect has put forward the fact that the elements of the robot—nacelle, posts and structure-should not be hidden by choosing elements visually similar to those of the building structure: different colors and patterns from the ones used for the building should be chosen for these elements.

\section{Technical Description of the Elected Design}

\subsection{General Layout}

In order to keep out from the cushions covering the façade, the pulley's positions have been set at 1 and $5 \mathrm{~m}$ away from the façade. There are two cables at each of the four corners of the workspace. The centre point of the robot nacelle will move nominally $3 \mathrm{~m}$ away from the façade.

As mentioned above, the main concern being the lateral stiffness of the robot against wind to avoid that the nacelle hits the building when a wind gust occurs, a fully constrained design has been chosen. As explained later on, a state of the art control law will allow changing the robot stiffness and power consumption in function of the wind by modulating inner constraints in the robot (Fig. 5).

The layout of the fixing points of the cables on the nacelle has been chosen accordingly to this constraint. The robot's nacelle precise design has not yet been defined, as there are still theoretical developments and tests underway to choose the best configuration when dealing with this constraint. The goal is to find a good compromise between having a reasonably high stiffness in all directions (and especially in the critical building transverse direction) and at the same time avoiding cable interferences in the workspace. The first simulations and the test on the real prototype have been carried out with a parallelepiped platform with a cable at each vertex. Another configuration featuring two cables attached at each vertex of a tetrahedron has been successfully tested in the simulations program. In addition, the pulley's positions will be designed so that they may be placed in different positions on the beam once the robot has been built. 

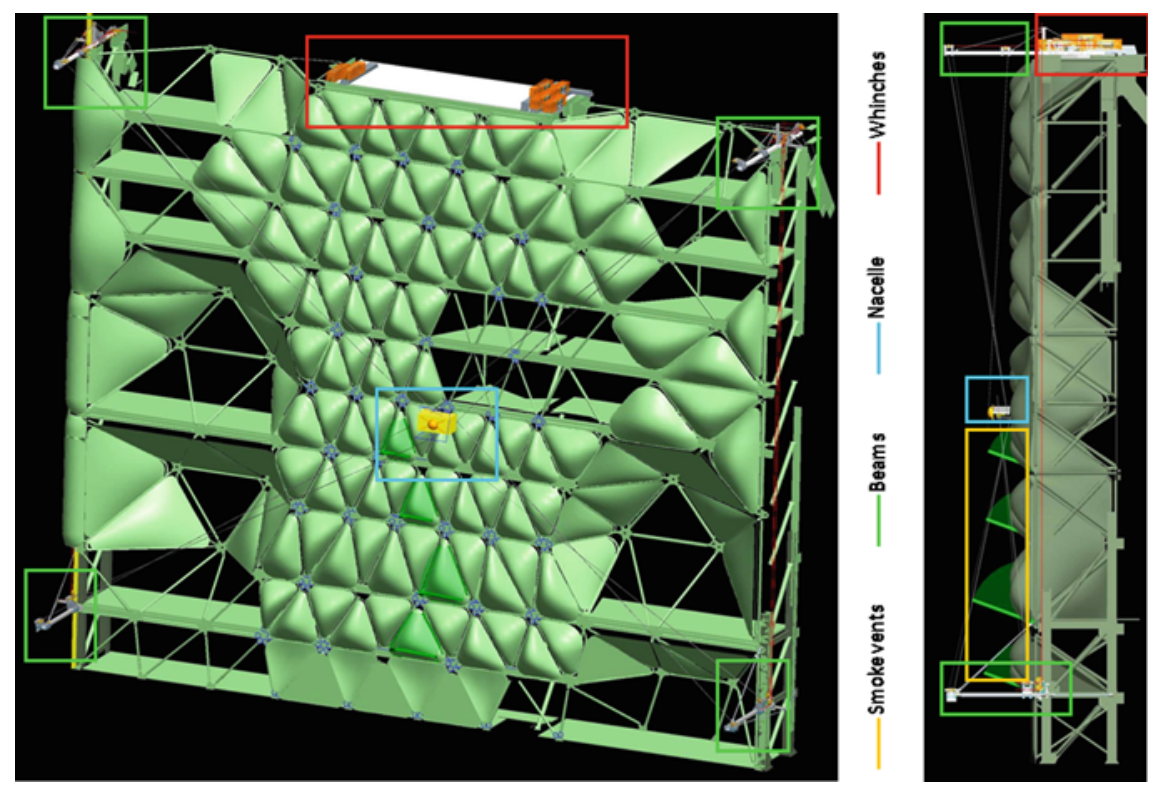

Fig. 5 General CAD view of the parallel cable-driven robot on the Media-TIC façade. Colored boxes indicate the position of the different subsystems. Nacelle is shown in parked position
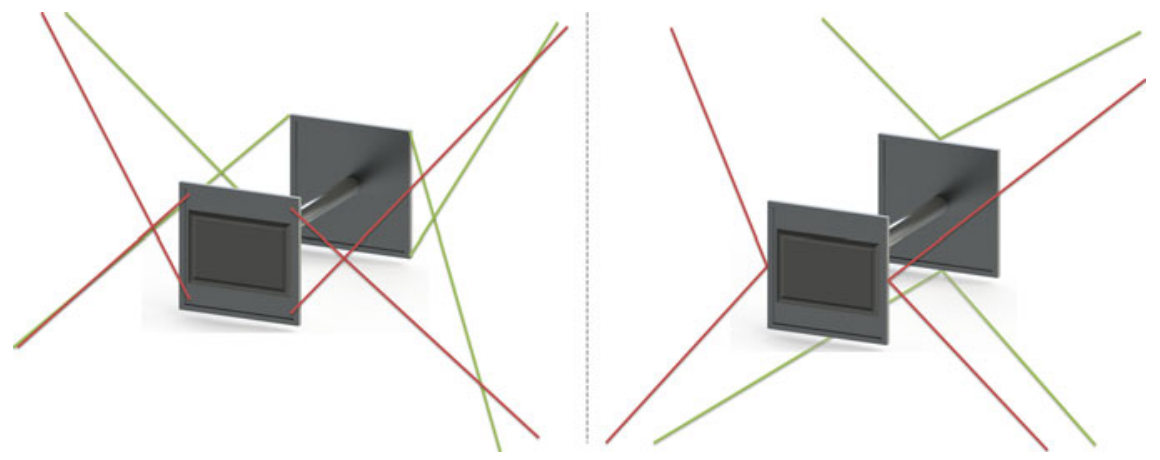

Fig. 6 CAD view of the preliminary designs of the nacelles. Right figure shows the parallelepiped nacelle, left figure shows the tetrahedron nacelle. Front panel cables are attached to the back drawing points, while back panel cable are to the front drawing points

Figure 5 shows the arrangement of cables on the platform that have been studied so far. The nacelle dimensions have been selected to keep a low profile against wind transversal to the façade. Fixing points are $2 \mathrm{~m}$ away on the horizontal axis parallel to the façade, $1 \mathrm{~m}$ away on the vertical axis and $1.5 \mathrm{~m}$ wide on the horizontal transverse axis. In the nacelle, a $0.5 \mathrm{~m}$ diameter cylinder will include all the hardware (Fig. 6).

The issue with the smoke vents has been dealt with using the following strategy. When a fire alarm occurs, the centre point of the nacelle slides outward to the building 
by $1.5 \mathrm{~m}$, letting it avoid the smoke vents by $0.5 \mathrm{~m}$. The deployment of the smoke vent takes $3 \mathrm{~s}$ : considering the winch speeds, the robot is able to reach the safe position before the smoke vents are deployed. The nacelle is then moved and docked safely to its cradle once the smoke vents are opened.

The cradle of the nacelle will be positioned at one of the balconies of the building. In order to dock to it, the nacelle will have to slide closer to the façade, the position of the cradle has therefore been set in function of the position of the elements of the façade in the way, in particular the smoke vents. The cradle itself will be able to open and close to leave way for the nacelle when the robot operates.

\subsection{Dimensioning}

Considering the different systems to be carried in the nacelle, its mass has been evaluated at maximum $200 \mathrm{~kg}$. Primary calculations taking into account platform mass, cable mass and wind load on both the platform and the cable lead to consider $10 \mathrm{kN}$ as the maximum force in each cable and a steel cable diameter of $12 \mathrm{~mm}$ (with a 10x security factor against breaking) to reach every point in the workspace considered in the specification section. The cable construction is standard $6 \times 36$ construction with a metallic $7 \times 7$ core, and therefore generates rotation when pulled, but shows low torsional stiffness as well.

The resulting wrench transmitted from the posts to the structure has been evaluated at maximum $50 \mathrm{kNm}$ of torque and $63 \mathrm{kN}$ of force for each of the posts.

Nacelle speed has been set to $1.5 \mathrm{~m} / \mathrm{s}$ in order to limit issues on the winches due to high cable linear speed. As a result, the motor power needed for each cable is $15 \mathrm{~kW}$. At most, the installation will have to be supplied $30 \mathrm{~kW}$ at a time, which means the windmills will have to generate power at their nominal level of $3 \mathrm{~kW}$ for 10 hours before 1 hour of operation at full current can be carried out.

\subsection{Control Scheme}

A control architecture that is able to take into account the actuation redundancy has been set up, tested and validated through simulation. Its validation took place when it has been successfully implemented on a real robot prototype.

The objective of this control law is to take into account the redundancy during the movements of the robot to prevent any cable from sagging under low tension. A hybrid position / force control law has been set up, based on research carried out by Lafourcade [9]. It consists in synthesizing a command of the cable tension integrating two parts: one generating movement of the nacelle, $\boldsymbol{\tau}_{\text {range }}$, and another one making sure that all the cables are under tension during movement, $\boldsymbol{\tau}_{\text {kernel. }}$. The first part generating movement can be obtained by a control law in the operational space or in the joint space. The second part, ensuring tension in every cable, is derived by 


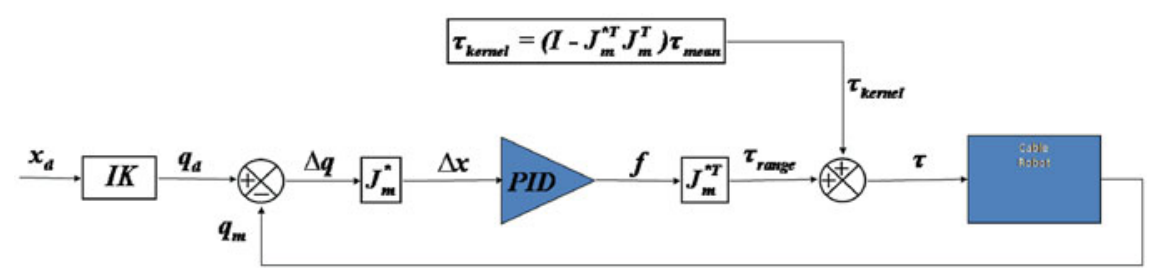

Fig. 7 Implementation of the control law with $\tau_{\text {range }}$ being generated in the operational space

projecting a mean desired cable tension on the kernel of the matrix $\mathbf{J}_{m}^{T}$ linking the cable tensions with the external wrench applied to the nacelle.

Preliminary results in stiffness estimation of fully constrained parallel cabledriven robots suggest that, with the layout of the Media-TIC robot, its transverse stiffness is directly linked to the mean cable tension. As a result, the control law set in place may be used to increase the stiffness of the parallel cable-driven robot during days when wind is blowing, with a tradeoff on the total power required for operation. During days with low wind, the robot will operate with a lower mean cable tension. This will lead to a lower transversal stiffness and a lower energy consumption for a given nacelle speed, in line with the concept of Media-TIC (Fig. 7).

\subsection{Robot Subsystems}

\section{Winches}

Winch motors have been chosen among the B\&R motor range to deliver the appropriate power. The $8 \mathrm{LSA} 85$ motor has been chosen, featuring up to $72 \mathrm{Nm}$ at $2,000 \mathrm{rpm}$, and $94 \mathrm{Nm}$ at stall. It drives the $292 \mathrm{~mm}$ primary diameter drum with a reduction ratio of $1: 16$, which leads to a maximum cable speed of $1,9 \mathrm{~m} / \mathrm{s}$.

In addition to the constraint of having a security factor of 10, in order to comply with the DIN 56921 standards, the winches must be equipped with two current loss brakes, one of which being connected directly on the drum. One of these brakes is included in the $8 \mathrm{LSA} 85$ motor. The second brake is a double rotor elevator brake rated at $800 \mathrm{Nm}$ for each rotor.

The length of cable reeled in and out is monitored via the rotation of the spool using an absolute rotary position sensor. In addition, the winch is fitted with limit switches. In order to avoid unreeling the cable when applying negative tensions in the cable, rollers are maintaining the cable in place on the drum using springs.

Winches are powered using the ACOPOSmulti range from B\&R, both gathering data from the sensors and driving the motors, linked together and to a central field computer featuring the control loop through a POWERLINK field bus. 


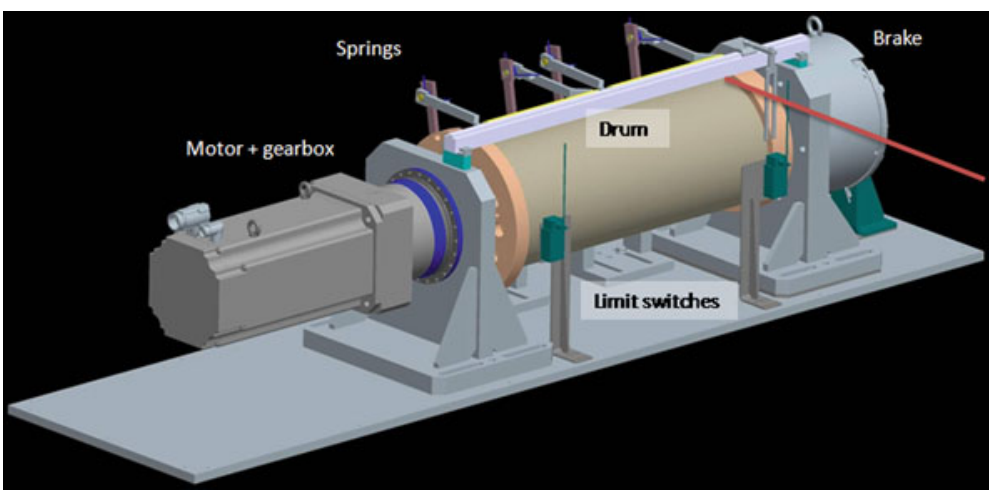

Fig. 8 CAD view of a winch

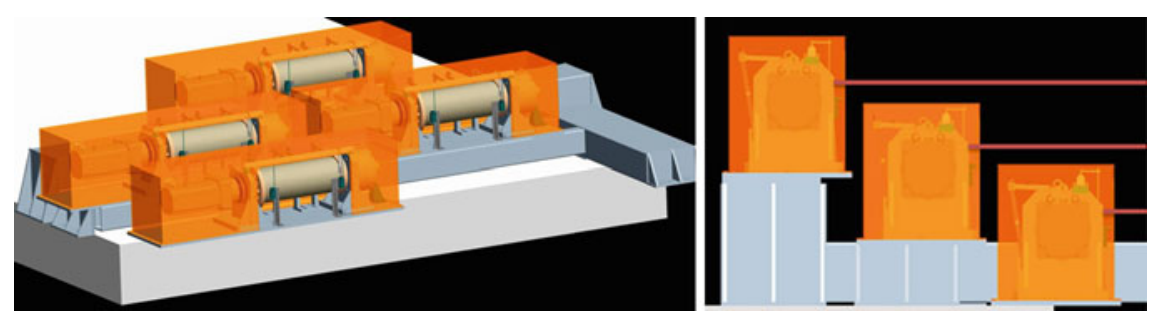

Fig. 9 Arrangement of the winches on the roof of the building

Finally, the drums are enclosed in boxes to prevent weather damage, since they are installed in open air on the roof of the building. They are placed so that there is no interference between the different cables and the winches (Figs. 8 and 9).

\section{Cable Circulation}

With the winches on the roof of the building, the cables must be directed from there to the positions of the pulleys at the four corners of the façade. The circulation must also include a force sensing system, giving the tension in each cable. The force sensor will be a shear stress sensor placed on the last fixed pulley of the circulation. Stress sensors will be monitored using B\&R X67 hardware specially designed for remotely placed sensors, addressed via POWERLINK.

The upper beams, supporting the pulleys for the cables attached to the nacelle by the top, redirect all the cables from the winches to the pulleys and to the lower beams. Force sensors for the upper cables are placed on the pulley directing the cable from the drum to the winches. The fixed pulleys for the lower cables are not instrumented. Cable tendons are placed to limit the bending of the beam under load. 


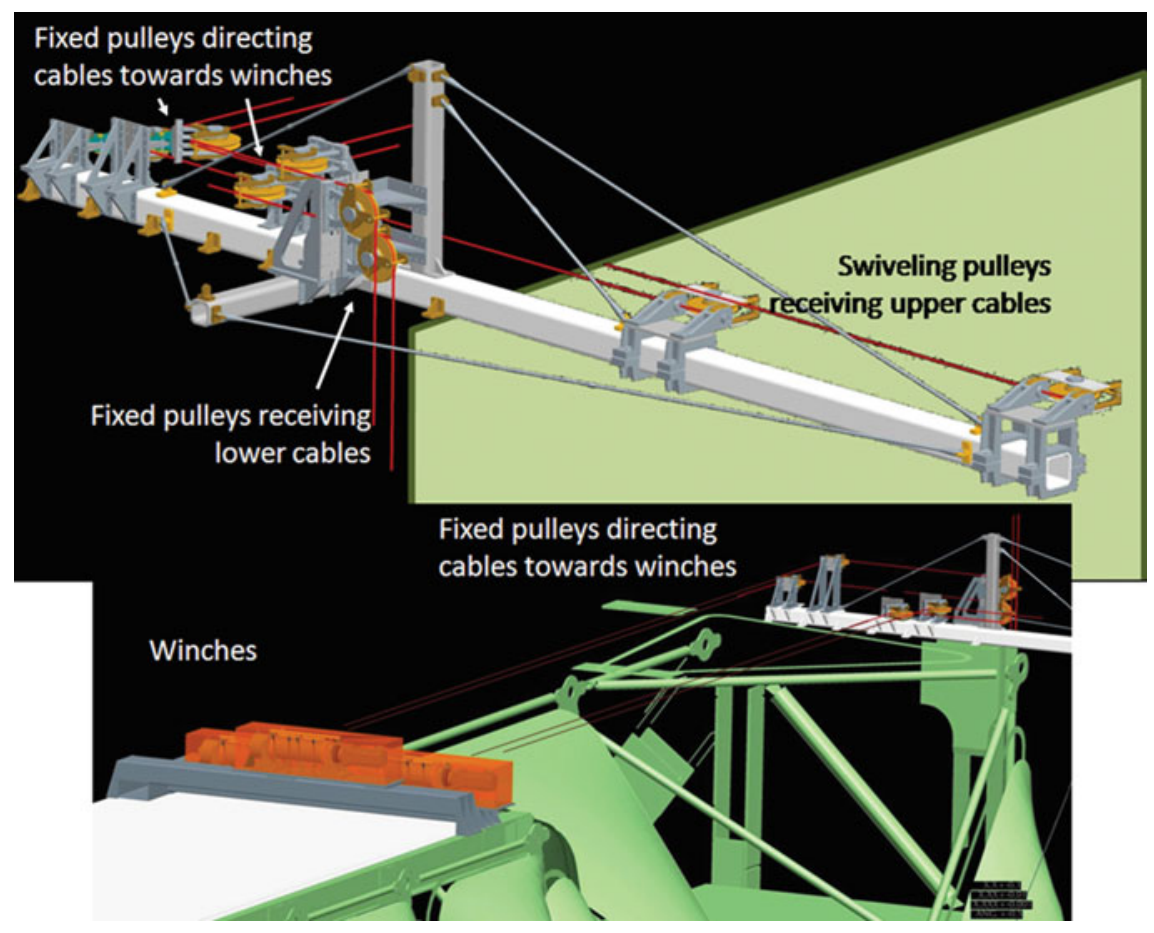

Fig. 10 Upper beam arrangements of the different pulleys. Up: arrangement of the upper left beam, upper right beam being symmetric. Down: circulation of cable between the winches and the upper right beam

The lower beams direct the cables from the upper beams to the output pulleys. The fixed pulleys on the lower beams are equipped with force sensors. Once again, cable tendons are fixed between the beam and the structure of the building to avoid unacceptable bending of the beams (Figs. 10 and 11).

As shown in Fig. 12, the output pulleys are assembled on a bearing whose axis is collinear to the axis of the cable coming from the fixed pulleys. The cable runs through one of the bearings. Here we are taking advantage of the low stiffness of the cable, due to the $6 \times 36+7 \times 7$ construction, which might not be possible with a non-rotating cable. The pulley orientation is determined by the direction on which the cable pulls. The cable is kept in place in the pulley by rods at the exit of the pulley.

The block in itself is clamped to the beam. It will allow keeping on with the optimal configuration determination through simulations and tests, and constructing the most optimal configuration when the robot will be ready for start-up. 


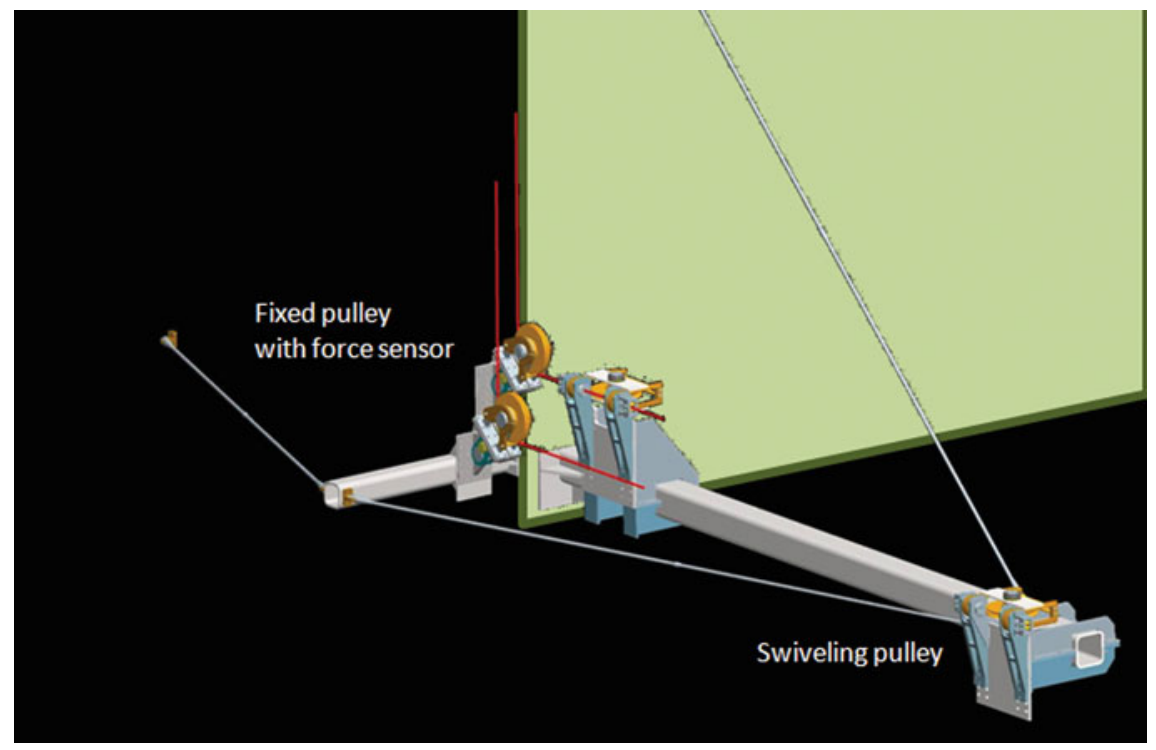

Fig. 11 Lower left beam. Lower right beam is symmetric

\section{Nacelle}

As explained above in this paper, the detailed configuration of the nacelle has not yet been chosen. However, the global shape of the platform has been determined with the goal of limiting the force due to the pressure of the wind. The nacelle will also feature several electronic hardware items, such as a computer with GPRS connection, batteries, lightings, screen, speakers, weather sensors and cameras partly powered by solar panels. The nacelle cradle will allow recharging the batteries when the nacelle is docked. All of these items are housed in a $50 \mathrm{~cm}$ diameter cylinder and fixed on a central axis, to which will be fixed as well the structural beams holding the cables.

\section{Conclusion}

This paper presented the implementation of a parallel cable-driven robot on the façade of the Media-TIC building located in the city of Barcelona, Spain. This robot is intended to work as a sensor for monitoring the environment and also as an interface between the building and its occupiers and visitors. Various constraints, due to normative, structural and aesthetic reasons, were described along with the elected detailed design of the robot that complies with them. One of the main technical issues is to design a parallel cable-driven robot with a lateral stiffness sufficient to withstand forces due to the wind. Here, this has been achieved by means of an appropriate layout of the cables in a fully constrained configuration. Besides, the selected control 


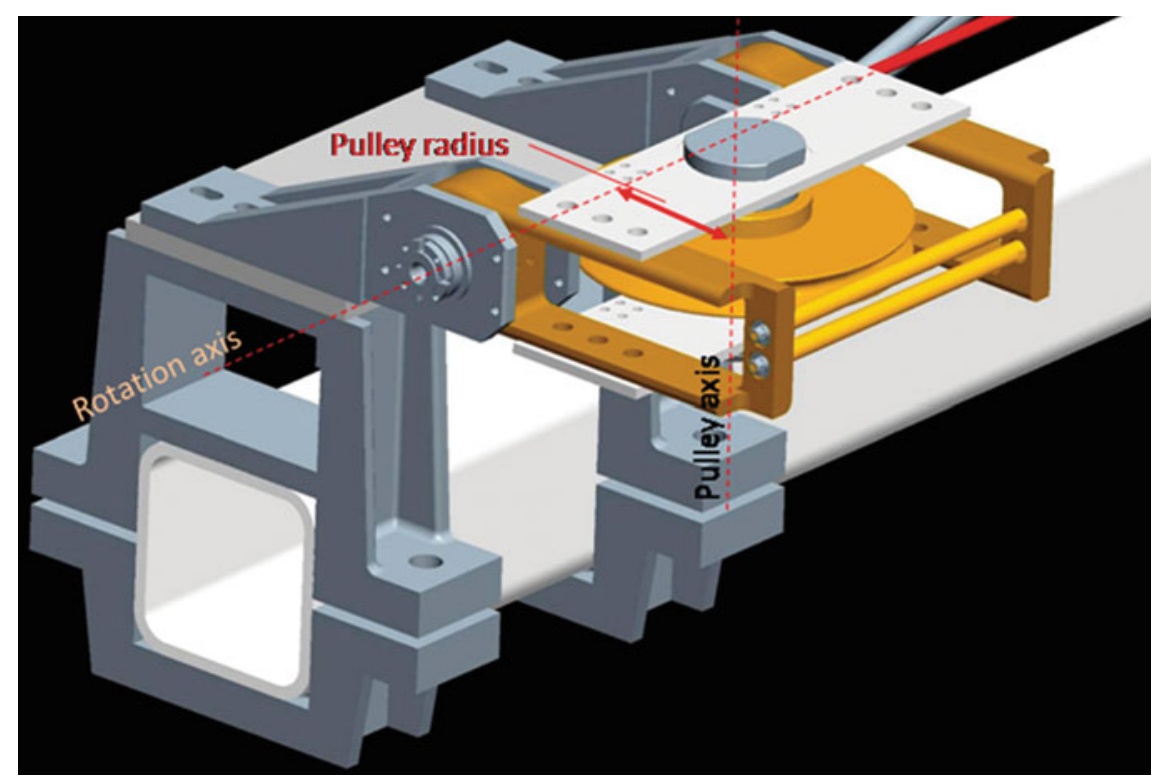

Fig. 12 Close view of the swiveling output pulley

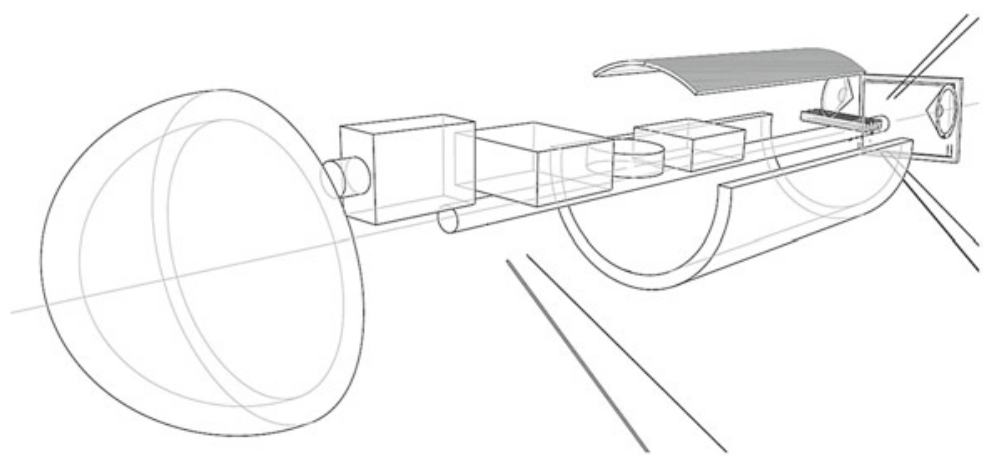

Fig. 13 View of the internal arrangement of the nacelle. Credits: Cloud9

law is able to modify the robot stiffness with a tradeoff between stiffness and energy consumption.

The robot has not yet been realized nor installed on the building façade. Indeed, we are still currently waiting for the construction permits to carry on with the installation of the robot.

Acknowledgments The authors would like to thank El Consorci and the 22@ Office of the City of Barcelona, as well as the team of Cloud9 and in particular Enric Ruiz-Geli, the architect of the building, for allowing us to consider this application on the Media-TIC building and their 
participation to its design. The contribution of the company B\&R to the project with the design of the system control is also greatly acknowledged.

\section{References}

1. SkyCam: http://skycam.tv/

2. SpyderCam: (2012). http://spydercam.com/

3. Merlet, J.-P.: Kinematics of the wire-driven parallel robot MARIONET using linear actuators. In: IEEE International Conference of Robotics and Automation, Passadena, CA, USA (2008)

4. Merlet, J.-P., Daney, D., Winch, A., Needs, A.A.: A portable, modular parallel wire crane for rescue operations. In: IEEE International Conference on Robotics and Automation. pp. 28342839, Anchorage, AK, USA (2010). doi:10.1109/ROBOT.2010.5509299

5. Ming, A., Higuchi, T.: Study on multiple degree-of-freedom positioning mechanism using wires. II: Development of a planar completely restrained positioning mechanism. 3, Tokyo, Japan : Japan Society for Precision Engineering. Int. J. Jpn. Soc. Precis. Eng. 28, 235-242 (1991)

6. Gouttefarde, M., Gosselin, M.: Analysis of the wrench-closure workspace of planar parallel cable-driven mechanisms. IEEE Trans. Robot. 22(3), 434-445 (2006)

7. Ottaviano, E., Ceccarelli, M., Paone, A., et Carbone, G.: A low-cost easy operation 4-cable driven parallel manipulator. In: IEEE International Conference on Robotics and Automation, pp. 4008-4013. Barcelona, Spain (2005). doi:10.1109/ROBOT.2005.1570734

8. Hiller, M., Fang, S., Mielczarek, R., Verhoeven, R., Franitza, D.: Design, analysis and realization of tendon-based parallel manipulators. 4, s.l. : Elsevier, Mechanism Mach. Theor. 40, 429-445 (2005). doi:10.1016/j.mechmachtheory.2004.08.002

9. Lafourcade, P., Zheng, Y.-Q. and Liu, X.-W.: Stiffness analysis of wire-driven kinematic manipulators. In: 11th World Congress in Mechanism and Machine Science, China Machine Press, Tianjin, China (2004) 